Volodymyr Mizyuk and Volodymyr Shibanov

\title{
CALCULATION OF NMR ${ }^{13} \mathrm{C}$ SPECTRA OF PENTANOL AND ITS ESTERS AS AN EXAMPLE OF EFFECTIVE APPLICATION OF ADDITIVITY OF CHEMICAL SHIFT INCREMENTS FOR ATTRIBUTED SIGNALS IN ALIPHATIC COMPOUNDS SPECTRA
}

\author{
Ukrainian Academy of Printing, Lviv, Ukraine
}

Received: N ovember 01, 2009 / Accepted: J anuary 21, 2010

(C) Mizyuk V., Shibanov V., 2010

\begin{abstract}
Application of increments additivity allows to attribute closed by value signals in the area of $28 \mathrm{ppm}$ in NMR ${ }^{13} \mathrm{C}$ spectra of 1-pentanol (I) and its esters (II, III) for $\mathrm{C}^{2}$ and $\mathrm{C}^{3}$ atoms during calculations of $\delta^{C}{ }_{2}$ and $\delta^{C}{ }_{3}$ chemical shifts. In case of pentylformate (IIa) on the basis of calculated data it has been suggested to interchange attributions made by authors [2].
\end{abstract}

Keywords: NMR ${ }^{13} \mathrm{C}$ spectra, basic and differential (spectral) parameters, 1-pentanol and its esters, chemical shift increments, calculated parameters.

\section{Introduction}

Alkylbenzoates and alkylbenzoylformates are byproducts [1] of phenylglyoxal acetals synthesis, which are effective photoinitiators of radical processes. Studying their spectral peculiarities we noticed the close values of basic spectral parameters $\delta^{C}{ }_{i}$ for atoms $\mathrm{C}^{2}\left(\delta^{C}{ }_{2}\right)$ and $\mathrm{C}^{3}\left(\delta^{C}{ }_{3}\right)$ (approximately $28 \mathrm{ppm}$ ) in NMR ${ }^{13} \mathrm{C}$ spectra of 1-pentanol (I) esters - pentylbenzoate (IId) and pentylbenzoylformate (IIe). Such peculiarity is also typical of spectral parameters of other 1-pentanol esters, derivatives of aliphatic acids (IIa-IIc), pentyltosylate (III), which is structurally close to esters (II), and partially of 1-pentanol by itself $[2,3]$.

$$
\begin{aligned}
& \text { R-O-C } \mathrm{C}_{2}^{1} \mathrm{H}_{2}-\mathrm{C}^{2} \mathrm{H}_{2}-\mathrm{C}^{3} \mathrm{H}_{2}-\mathrm{C}^{4} \mathrm{H}_{2}-\mathrm{C}^{5} \mathrm{H}_{3} \\
& \text { I, III } \quad \sim 28 \mathrm{ppm} \\
& \mathrm{R}^{\mathrm{I}}-\mathrm{C}(\mathrm{O})-\mathrm{O}-\mathrm{C}^{1} \mathrm{H}_{2}-\mathrm{C}^{2} \mathrm{H}_{2}-\mathrm{C}^{3} \mathrm{H}_{2}-\mathrm{C}^{4} \mathrm{H}_{2}-\mathrm{C}^{5} \mathrm{H}_{3} \\
& \text { II(a-e) } \\
& \sim 28 \mathrm{ppm}
\end{aligned}
$$

where $\mathrm{R}=\mathrm{H}(\mathrm{I}), \mathrm{p}-\mathrm{CH}_{3} \mathrm{C}_{6} \mathrm{H}_{4} \mathrm{SO}_{2}$ (III); $\mathrm{R}^{\mathrm{I}}=\mathrm{H}$ (a), $\mathrm{CH}_{3}$ (b), $\mathrm{n}-\mathrm{C}_{3} \mathrm{H}_{7}(\mathrm{c}), \mathrm{C}_{6} \mathrm{H}_{5}$ (d), $\mathrm{C}_{6} \mathrm{H}_{5} \mathrm{C}=\mathrm{O}$ (e)

It should be of interest to examine the reasons of the observed closeness of $\delta^{P}$ and $\delta_{3}^{P}$ values and find the method of reliable attributions of corresponding signals to $\mathrm{C}^{2}$ and $\mathrm{C}^{3}$ atoms in NMR ${ }^{13} \mathrm{C}$ spectra.

\section{Experimental}

In order to minimize inaccuracies connected with different $\delta^{C}{ }_{i}$ basic parameters for nuclei of $i$ - carbon atoms in the same compound, it is desirable that all $\delta^{C}$ values be taken from one informational source in order that all the data are in agreement. However, we had to use the data from two sources, which are the most reliable ones, to our mind. The main source is an internet site [2] and the additional source is an atlas of NMR spectra, Aldrich firm ${ }^{1}$ [3]. Values $\delta^{C}{ }_{i}$ for the same compounds in [2] and [3] have an accuracy of $0.01 \mathrm{ppm}$.

Some necessary data are absent in [3] but they are presented in [2]; however the data from [3] supplement the data from [2], confirming (or disproving) the correctness of signal attribution made in [2]. We decided to "combine" the data from both sources because $\delta^{C}$, values for the same compounds coincide with the accuracy of $0.1 \mathrm{ppm}$ or differ by less than $0.2 \mathrm{ppm}$ and only in rare cases the difference is greater. Therefore, the difference less than $0.1 \mathrm{ppm}$ is considered as a very good one. The good coincidence is achieved when the difference is within the interval from 0.1 to $0.2 \mathrm{ppm}$. If the difference is higher than $0.2 \mathrm{ppm}$, we consider the calculated value as

${ }^{1}$ The criterion of choosing "main" and "additional" sources is based on the fact that signals attribution in [2] was made by authors and this fact is absent in [3]. However, spectra in [3] were obtained from the instrument with working frequency $75 \mathrm{MHz}$, which is a great advantage. The main part of the data in [2] were obtained from the device with the frequency $15,22.5$ and $25 \mathrm{MHz}$, hence they are less accurate. Only smaller part of the data in [2] were recorded at higher frequency - 50 or $100 \mathrm{MHz}$ and are in better agreement with analogous parameters from [3]. 
unsatisfactory and special comments are necessary in such case.

For all spectra in [2] the authors gave their own signals attribution. We do not agree with them in some cases. In those cases when authors from [2] consider that attribution of existing signals to absorption of specific nuclei of carbon atoms $\left(\mathrm{C}^{2}\right.$ and $\mathrm{C}^{3}$ in our case $)$ is insufficiently well-reasoned, both numerals have superscript *. It means that authors allow to exchange attributions given by them (e.g. pentylbutyrate IIc, pentylbenzoate IId and pentyltosylate III).

Table 1 presents values of basic spectral parameters $\left(\delta^{C}{ }_{2}\right)$ and $\left(\delta^{C}{ }_{3}\right)$ in compounds (I)-(III) with corresponding references and calculated differential parameters $\Delta \delta^{C}{ }_{2-3,}$ which are the differences: $\Delta \delta^{C}{ }_{2-3}=\delta^{C}{ }_{2}-\delta^{C}{ }_{3}$. Our preliminary attributions of signals numerical values in $\mathrm{NMR}{ }^{13} \mathrm{C}$ spectra in [3] to $\mathrm{C}^{2}-\mathrm{C}^{3}$ atoms absorption are given in parentheses (by analogy with [2]).

Preliminary attributions between signals in NMR ${ }^{13} \mathrm{C}$ spectra of (I) - (III) compounds (given in [2, 3]) to $\mathrm{C}^{2}-\mathrm{C}^{3}$ atoms

\begin{tabular}{|c|c|c|c|c|c|c|}
\hline Spectral parameters in compounds, ppm & I & IIa & IIb & IIc & IId & III \\
\hline \multirow{2}{*}{$\delta^{C}{ }_{2}$} & $32.53[2]$ & $28.11[2]$ & $28.48[2]$ & $28.51^{*}[2]$ & $28.58^{*}[2]$ & $28.61^{*}[2]$ \\
& $(32.48)[3]$ & & $(28.44)[3]$ & $(28.40)[3]$ & & \\
\hline \multirow{2}{*}{$\delta^{C}{ }_{3}$} & $28.17[2]$ & $28.36[2]$ & $28.23[2]$ & $28.23^{*}[2]$ & $28.32^{*}[2]$ & $27.53^{*}[2]$ \\
& $(28.05)[3]$ & & $(28.18)[3]$ & $(28.13)[3]$ & & \\
\hline \multirow{2}{*}{$\Delta \delta^{C}{ }_{2-3}$} & +4.36 & -0.25 & +0.25 & $+0.28^{*}$ & $+0.26^{*}$ & $+1.08^{*}$ \\
& $(+4.43)$ & & $(+0.26)$ & $(+0.27)$ & & \\
\hline
\end{tabular}

\section{Results and Discussion}

Using developed conception about additivity of chemical shifts increments during calculations of $\delta^{C}$ values in $\mathrm{CH}_{3}\left(\mathrm{CH}_{2}\right)_{\mathrm{n}} \mathrm{X}$ [4] we calculated values of basic parameters $\delta^{C}{ }_{1}-\delta^{C}{ }_{5}$ in NMR ${ }^{13} \mathrm{C}$ spectra of pentoxyl fragment of compounds (I-III). The comparison of calculated and experimental data allows us to revise some attributions from [2], including $\delta^{C}{ }_{2}$ and $\delta^{C}$ parameters. For instance, we consider it would be advisable to interchange correlations for $\delta^{I I a}{ }_{2}$ and $\delta^{I I a}{ }_{3}$ parameters in a spectrum of pentylformate IIa given in [2]. The application of calculated data allows also the final well-reasoned signals correlation [3] in spectra of compounds (I)-(III) (see Table 2).

Calculated values for every $\delta^{C}{ }_{i}$ parameter are given in the left column of the Table 2. Our correlations of experimental values [2] for signals of compounds (I)-(III) are given in the upper part of the right column in bold type. Our final correlations of these signals in the spectra [3] of the mentioned compounds are written in bold italic type.

Final attributions of experimental $[2,3]$ and calculated signals in $N M R{ }^{13} \mathrm{C}$ spectra of compounds (I)-(III) to $\mathrm{C}^{2}-\mathrm{C}^{3}$ atoms

\begin{tabular}{|c|c|c|c|c|c|c|c|c|c|c|}
\hline \multirow{2}{*}{$\begin{array}{c}\delta^{C}{ }_{i} \text { values }(\mathrm{ppm}) \text { in } \\
\text { compounds }\end{array}$} & \multicolumn{2}{|c|}{$\delta_{1}^{C}$} & \multicolumn{2}{|c|}{$\delta^{C}{ }_{2}$} & \multicolumn{2}{|c|}{$\delta_{3}^{C_{3}}$} & \multicolumn{2}{|c|}{$\delta_{4}^{C}$} & \multicolumn{2}{|c|}{$\delta^{C}{ }_{5}$} \\
\hline & Calc. & Exp. & Calc. & Exp. & Calc. & Exp. & Calc. & Exp. & Calc. & Exp. \\
\hline \multirow{2}{*}{ I } & \multirow{2}{*}{62.95} & 62.68 & \multirow{2}{*}{32.55} & 32.53 & \multirow{2}{*}{28.05} & 28.17 & \multirow{2}{*}{22.50} & 22.66 & \multirow{2}{*}{14.05} & 14.09 \\
\hline & & 62.79 & & 32.48 & & 28.05 & & 22.58 & & 14.07 \\
\hline \multirow{2}{*}{ IIa } & \multirow{2}{*}{64.05} & 64.12 & \multirow{2}{*}{28.35} & 28.36 & \multirow{2}{*}{28.15} & 28.11 & \multirow{2}{*}{22.30} & 22.38 & \multirow{2}{*}{13.90} & 13.96 \\
\hline & & - & & - & & - & & - & & - \\
\hline \multirow{2}{*}{$\mathrm{IIb}$} & \multirow{2}{*}{64.60} & 64.64 & \multirow{2}{*}{28.40} & 28.48 & \multirow{2}{*}{28.20} & 28.23 & \multirow{2}{*}{22.30} & 22.46 & \multirow{2}{*}{13.90} & 13.99 \\
\hline & & 64.65 & & 28.44 & & 28.18 & & 22.39 & & 13.91 \\
\hline \multirow{2}{*}{ IIc } & \multirow{2}{*}{62.95} & 62.68 & \multirow{2}{*}{28.40} & 28.51 & \multirow{2}{*}{28.20} & 28.23 & \multirow{2}{*}{22.30} & 22.44 & \multirow{2}{*}{13.90} & 13.99 \\
\hline & & 62.79 & & 28.40 & & 28.13 & & 22.36 & & 13.98 \\
\hline \multirow{2}{*}{ IId } & \multirow{2}{*}{65.05} & 65.12 & \multirow{2}{*}{28.50} & 28.58 & \multirow{2}{*}{28.35} & 28.32 & \multirow{2}{*}{22.35} & 22.41 & \multirow{2}{*}{13.90} & 13.94 \\
\hline & & - & & - & & - & & - & & - \\
\hline \multirow{2}{*}{ III } & 7070 & 70.72 & 2855 & $2^{28.61}{ }^{*}$ & 27,60 & 27.53* & 2185 & 22.03 & 1370 & $\mathbf{1 3 . 7 5}$ \\
\hline & & - & & - & & - & & - & & - \\
\hline
\end{tabular}

Below are the arguments which were the bases for our final attributions represented in Table 2. 


\subsection{Calculation of Basic Parameters $\delta_{i}^{1}$ (including $\delta_{2}^{1}$ and $\delta_{3}^{1}$ ) and Differential Parameter $\Delta \delta^{1}{ }_{2.3}$ in NMR ${ }^{13} \mathrm{C}$ Spectra of 1-Pentanol (I)}

Authors [4] present a concept of increments used for the calculation of values of basic spectral parameters $\delta^{C}{ }_{i}$ in linear substituted aliphatic compounds by general formula $\mathrm{CH}_{3}\left(\mathrm{CH}_{2}\right)_{n} \mathrm{X}$. 1-Pentanol (I), as well as its esters (II-III) is a particular case of the mentioned general formula (where $\mathrm{n}=4$ and $\mathrm{X}=\mathrm{OH}$ or OR for esters). All increments are divided into two groups depending upon their location in the chain of carbon atoms which they refer to. Increments of the first group (for alkyl end of the molecule) are marked by symbols $\Delta \delta^{C}$; increments of the second group are marked as $\Delta \delta^{C}$.

Due to the rules of chemical nomenclature for $\mathrm{CH}_{3}\left(\mathrm{CH}_{2}\right)_{\mathrm{n}} \mathrm{X}$ compounds the numeration of carbon atoms in the chain starts from the atom connected with the substituent $\mathrm{X}$ (therefore carbon atom of methyl group is marked as $\mathrm{C}^{\omega}$ ). The values of the first five differed from zero increments $\Delta \delta^{C}{ }_{r}(r=1-5)$ are the same for all classes of alkyl compounds by general formula $\mathrm{CH}_{3}\left(\mathrm{CH}_{2}\right)_{\mathrm{n}} \mathrm{X}$ and equal to: $\Delta \delta^{C}{ }_{\omega}=-15.65 \mathrm{ppm}, \Delta \delta^{C}{ }_{\omega-1}=-7.05 \mathrm{ppm}, \Delta \delta^{C}{ }_{\omega-2}=$ $=+2.25 \mathrm{ppm}, \Delta \delta^{C}{ }_{\omega-3}=-0.30 \mathrm{ppm}, \Delta \delta^{C}{ }_{\omega-4}=-0.05 \mathrm{ppm}$. The set of $\Delta \delta^{C}$ increments is different for every substituent and depends upon peculiarities of its chemical structure [4].

For alcohols the increments values $\Delta \delta^{c}$ for functionalized (hydroxyl) end of the molecule were taken from [4]. These values, as well as increments $\Delta \delta^{c}{ }_{s}(s=1-8)$ rounded to the nearest value divisible by $0.05 \mathrm{ppm}$, for other classes of compounds (II)-(III) are given in Table 3.

Having values of increments $\Delta \delta^{C}{ }_{r}(r=1-5)$ and $\Delta \delta^{C}{ }_{s}(s=1-8)$ we can calculate each of the five values $\Delta \delta^{c}{ }_{v}{ }_{v}(v=1-5)$ for 1-pentanol by formula (1) taken from [4]:

$$
\delta^{C}{ }_{i}=\delta^{C}{ }_{v}=\delta^{C}{ }_{\text {mid. }}+\Delta \delta^{C}{ }_{r}+\Delta \delta^{C}{ }_{s}
$$

where $\delta^{C}{ }_{\text {mid }}$ is a chemical shift of carbon middle atoms in long-chain alkanes. It is a constant value equal to 29.75 ppm [4]. To illustrate the calculations of the basic spectral parameters $\delta^{C}{ }_{i}$ for 1-pentanol by formula (1) all necessary spectral parameters are listed in Table 4. For their convenient comparison with the calculated data parameters $\delta^{C}$ for 1-pentanol, taken from Table 2 are presented in bold type and the data attributed by us from [3] - in bold italic type.

We attribute calculated parameter $\delta^{1}{ }_{2}(32.55 \mathrm{ppm})$ to absorption of $\mathrm{C}^{2}$ atom, because it is practically equal to parameter $\delta^{l}(32.53 \mathrm{ppm})$ given in [2] and signal value $(32.48 \mathrm{ppm})$ available in spectrum I [3]. Such relation between calculated and experimental data is observed between calculated parameter $\delta^{1}{ }_{3}(28.05 \mathrm{ppm})$ and attributions $\delta^{l}(28.17 \mathrm{ppm})$ taken from [2]. The signal value available in spectrum [3] accurately coincides with the calculated value $\delta^{I}{ }_{3}(28.05 \mathrm{ppm})$. The calculated value of differential parameter $\Delta \delta^{l}{ }_{2-3}=4.50 \mathrm{ppm}$ is greater than that calculated from experimental data but it coincides well with the value calculated by the data from [2] (4.36 ppm)

Table 3

Increments $\Delta \delta^{c}{ }_{s}(s=1-8)$ for alcohols and their esters

\begin{tabular}{|c|c|c|c|c|c|c|c|c|}
\hline $\begin{array}{c}\text { Calculated increments for } \\
\mathrm{C}^{\mathrm{i}} \text { atoms in compounds }\end{array}$ & $\mathrm{C}^{1}$ & $\mathrm{C}^{2}$ & $\mathrm{C}^{3}$ & $\mathrm{C}^{4}$ & $\mathrm{C}^{5}$ & $\mathrm{C}^{6}$ & $\mathrm{C}^{7}$ & $\mathrm{C}^{8}$ \\
\hline Alcohols & +33.25 & +3.10 & -3.95 & -0.25 & -0.05 & 0 & 0 & 0 \\
\hline Formates & +34.35 & -1.15 & -3.85 & -0.45 & -0.20 & -0.15 & -0.05 & 0.00 \\
\hline Acetates & +34.90 & -1.05 & -3.80 & -0.45 & -0.20 & 0 & 0 & 0 \\
\hline Butyrates & +34.65 & -1.05 & -3.80 & -0.45 & -0.20 & -0.15 & -0.10 & -0.05 \\
\hline Benzoates & +35.35 & -0.95 & -3.65 & -0.40 & -0.20 & -0.15 & -0.05 & 0.00 \\
\hline Tosylates & +40.95 & -0.90 & -4.40 & -0.90 & -0.40 & -0.30 & -0.15 & -0.05 \\
\hline
\end{tabular}

Data for calculation by formula (1) of $\delta_{i}^{C}$ parameter for 1-pentanol (I)

\begin{tabular}{|l|c|c|c|c|c|}
\hline Calculation for $\mathrm{C}^{\mathrm{1}}$ atom & $\mathrm{C}^{\mathrm{l}}$ & $\mathrm{C}^{2}$ & $\mathrm{C}^{3}$ & $\mathrm{C}^{4}$ & $\mathrm{C}^{5}$ \\
\hline$\delta^{C}{ }_{\text {midd }}$. parameter & 29.75 & 29.75 & 29.75 & 29.75 & 29.75 \\
\hline$\Delta \delta^{C}{ }_{r}$ parameter & -0.05 & -0.30 & +2.25 & -7.00 & -15.65 \\
\hline$\Delta \delta^{C}{ }$ parameter & +33.25 & +3.10 & -3.95 & -0.25 & -0.05 \\
\hline$\delta^{C}{ }_{i}$ calculated parameter (equals to $\delta^{C}{ }_{v}$ ) in formula (1) & 62.95 & 32.55 & 28.05 & 22.50 & 14.05 \\
\hline$\delta^{C}{ }_{i}$ experimental parameter taken from $[2]$ & $\mathbf{6 2 . 6 8}$ & $\mathbf{3 2 . 5 3}$ & $\mathbf{2 8 . 1 7}$ & $\mathbf{2 2 . 6 6}$ & $\mathbf{1 4 . 0 9}$ \\
\hline$\delta^{C}{ }_{i}$ experimental parameter taken from spectrum in $[3]$ & $\mathbf{6 2 . 7 9}$ & $\mathbf{3 2 . 4 8}$ & $\mathbf{2 8 . 0 5}$ & $\mathbf{2 2 . 5 8}$ & $\mathbf{1 4 . 0 7}$ \\
\hline
\end{tabular}


and very well - with the values calculated by the data from [3] (4.43 ppm).

Calculated values of other basic spectral parameters of 1-pentanol $\left(\delta_{4}^{I} \delta_{5}^{I}\right.$ and $\delta^{I}{ }_{1}$ in less degree $\left.{ }^{2}\right)$ also coincide well with corresponding attributions given in [2] and signals discovered in the 1-pentanol spectrum [3]. Hence we may conclude that the used calculation method is an effective instrument which helps to attribute signals in NMR ${ }^{13} \mathrm{C}$ spectra of aliphatic compounds, e.g. in 1-pentanol spectrum given in [3].

\subsection{Calculation of Basic Parameters $\delta^{\prime \prime}$, (including $\delta_{2}{ }_{2}$ and $\delta_{3}{ }_{3}$ ) and Differential Parameter $\Delta \delta^{11}$ i. 3 in $M M^{13} C$ Spectra of 1-Pentanol Esters (IIa-IId)}

The basic parameters $\delta_{2}^{I I}$ and $\delta_{3}^{I I}$ in spectra of 1pentanol esters (II) were calculated in a similar way. Calculations of all five parameters $\delta_{i}^{I}$, as well as revision correlations [2] and peaks [3], are presented in Table 2.

\subsubsection{Pentylacetate (IIb)}

Using values of increments $\Delta \delta^{C}{ }_{s}(s=1-5)$ for acetates $\left(\mathrm{CH}_{3}\left(\mathrm{CH}_{2}\right)_{\mathrm{n}} \mathrm{X}\right.$, where $\left.\mathrm{X}=\mathrm{OAc}\right)$ from [4] and Table 3 , we calculated values $\delta^{I l}{ }^{I b}$ for pentylacetate (IIb) by formula (1), by analogy with the values $\delta^{I}$ for 1-pentanol (I). The results are presented in Table 2.

Calculated values of parameters $\delta^{I l b}{ }_{2}=28.40 \mathrm{ppm}$ and $\delta^{I I b}=28.20 \mathrm{ppm}$ are close to the experimental values given in [2] $\left(\delta^{I l}{ }_{2}=28.48 \mathrm{ppm}\right.$ and $\left.\delta^{I b}{ }_{3}=28.23 \mathrm{ppm}\right)$ and peak values in spectrum IIb in [3] $\left(\delta^{I l b^{3}}=28.44 \mathrm{ppm}\right.$ and $\delta^{I I b}{ }_{3}=28.18 \mathrm{ppm}$ ). The same as in case of 1-pentanol, the value of differential parameter $\Delta \delta^{I l b}{ }_{2-3}$ obtained from calculated parameters $(28.40-28.20=+0.20 \mathrm{ppm})$ agrees with the value $\Delta \delta^{I I b}{ }_{2-3}$ calculated using the data [2] $(28.48-28.23=+0.25 \mathrm{ppm})$ and the data [3] (28.44 $-28.18=+0.26 \mathrm{ppm}$ ), although they are somewhat more.

\subsubsection{Pentylbutyrate (IIC)}

For butyrates, as well as for other esters - formates and benzoates - increments $\Delta \delta^{c}{ }_{s}$ are absent in [4], hence it was necessary to calculate them. Every $\Delta \delta^{C}{ }_{s}$ increment is calculated by formula (2), which is deduced from formula (1), and the obtained value is rounded to the nearest number divisible by $0.05 \mathrm{ppm}$ :

$$
\Delta \delta^{C}{ }_{s}=\delta^{C}{ }_{v}-\delta^{C}{ }_{\text {mid. }}-\Delta \delta^{C}{ }_{r}
$$

For calculations of $\Delta \delta^{c}{ }_{s}$ increments we use spectral data of alkyl butyrates with the longest alkyl chains. Undecylbutyrate is such a compound in [2] and decylbutyrate - in [3]. By analogy with Table 4 all necessary spectral parameters from undecylbutyrate spectrum are tabulated in Table 5 for the illustration of the calculation of $\Delta \delta^{C}{ }_{s}$ increments. Since the value of parameter $\delta^{C}{ }_{9}$ is missed in undecylbutyrate spectrum [2], we put in parentheses the value $\delta^{c}{ }_{9}=\delta^{c}{ }^{\omega}-3=31.98 \mathrm{ppm}$, typical of analogous basic parameters $\delta^{{ }^{0.3}-3}$ for other long-chain esters. As it was mentioned above values $\delta^{C}{ }_{i}$ which may be exchanged are marked with * in spectral correlations given in [2]. However it will be shown further that in the given spectrum such exchange is not necessary.

To confirm the calculated values of $\delta^{C}{ }_{s}$ parameters we duplicated their calculation by formula (2) using signals in decylbutyrate spectrum taken from [3]. Their correlation has been done by us by analogy with that in undecylbutyrate spectrum in [2]. The following data are listed below: number of carbon atom of decylbutyrate alkoxyl group, value of $\delta^{C}{ }_{v}(v=1-10)$ from [3], value of $\Delta \delta^{C}{ }_{s}$ increment calculated by formula (2). Values of the same parameters calculated

Data for calculation of $\delta^{C}$ increments for butyrates by formula (2) using NMR ${ }^{13} \mathrm{C}$ spectrum of undecylbutyrate given in [2]

\begin{tabular}{|l|c|c|c|c|c|c|c|c|c|c|c|}
\hline $\begin{array}{c}\text { Calculation for } \\
\text { atom }\end{array}$ & $\mathrm{C}^{1}$ & $\mathrm{C}^{2}$ & $\mathrm{C}^{3}$ & $\mathrm{C}^{4}$ & $\mathrm{C}^{5}$ & $\mathrm{C}^{6}$ & $\mathrm{C}^{7}$ & $\mathrm{C}^{8}$ & $\mathrm{C}^{9}$ & $\mathrm{C}^{10}$ & $\mathrm{C}^{11}$ \\
\hline$\delta^{C}{ }_{\text {mid. }}$ parameter & 29.75 & 29.75 & 29.75 & 29.75 & 29.75 & 29.75 & 29.75 & 29.75 & 29.75 & 29.75 & 29.75 \\
\hline$\Delta \delta^{C}{ }_{r}$ parameter & 0.00 & 0.00 & 0.00 & 0.00 & 0.00 & 0.00 & -0.05 & -0.30 & +2.25 & -7.00 & -15.65 \\
\hline$\delta^{C}{ }$ parameter [2] & 64.41 & 28.71 & 25.97 & $29.28^{*}$ & $29.54^{*}$ & $29.62^{*}$ & $29.59^{*}$ & $29.35^{*}$ & $(31.98)$ & 22.70 & 14.11 \\
\hline $\begin{array}{l}\Delta \delta^{C}{ }_{s} \text { rounded } \\
\text { calculated } \\
\text { parameter }\end{array}$ & +34.65 & -1.05 & -3.80 & -0.45 & -0.20 & -0.15 & -0.10 & -0.10 & $(0.00 ?)$ & -0.05 & 0.00 \\
\hline
\end{tabular}

${ }^{2}$ The increment for $\mathrm{C}^{1}$ atom $\left(\Delta \delta^{C}{ }_{1}=+33.25 \mathrm{ppm}\right)$ given in Table 3 for alcohols is athe result of a compromise. If we use $\delta^{C}{ }_{1}$ values taken from spectra of long-chain alcohols [3] (as well as $\delta^{C}$, values from "high-frequency spectra" [2]), then exactly the value $\Delta \delta^{C}{ }_{l}=+33.25 \mathrm{ppm}$ is the most suitable. If we use spectra from [2] obtained using low-frequency instruments, then the value $\Delta \delta^{C}{ }_{1}=+33.15 \mathrm{ppm}$ is more founded. Since we assumed above that data which were obtained using high-frequency devices are more reliable, we choose $\Delta \delta^{C}{ }_{1}=+33.25 \mathrm{ppm}$ as a tabulated value. Apropos, if we use value $\Delta \delta^{C}{ }_{1}=+33.15$ ppm, then calculated value $\delta^{C}{ }_{1}=+62.85 \mathrm{ppm}$ agrees better with experimental value $\delta^{C}{ }_{1}=+62.68 \mathrm{ppm}$ in 1-pentanol spectrum taken from [2] and the best - with the signal of $62.79 \mathrm{ppm}$ presented in spectrum (I) taken from [3]. However for calculations of $\delta^{C}$, parameters for other alcohols the tabulated value $\Delta \delta^{C}{ }_{1}=+33.25 \mathrm{ppm}$ is the best. Therefore we assume that value $\delta^{C}{ }_{1}=+62.68 \mathrm{ppm}$ for 1-pentanol [2] is understated by some reasons. 
for undecylbutyrate (the data from Table 5) are in parentheses: $\mathrm{C}^{1}, 64.38,+34.65(+34.65) ; \mathrm{C}^{2}, 28.69,-1.05$ (-1.05); $\mathrm{C}^{3}, 25.96,-3.80(-3.80) ; \mathrm{C}^{4}, 29.29,-0.45(-0.45)$; $\mathrm{C}^{5}, 29.56,-0.20(-0.20) ; \mathrm{C}^{6}, 29.57,-0.15(-0.15) ; \mathrm{C}^{7}, 29.34$, $-0.10(-0.10) ; C^{8}, 31.93,-0.05(-0.10) ; C^{9}, 22.66,-0.10$ (0.00); $\mathrm{C}^{10}, 14.12,0.00(0.00)$.

The comparison of both sets of increments $\delta^{C}(s=1-10)$ for butyrates shows full data coincidence for the first seven carbon atoms of decyloxyl fragment. The value $\Delta \delta^{C}{ }_{8}=0.05 \mathrm{ppm}^{3}$ was chosen between two different increments for $\mathrm{C}^{8}$ atom and given in Table 3 .

Using calculated set of increments $\Delta \delta^{C}{ }_{s}(s=1-8)$ for $\left(\mathrm{CH}_{3}\left(\mathrm{CH}_{2}\right)_{\mathrm{n}} \mathrm{X}\right.$, where $\left.\mathrm{X}=\mathrm{OCOPr}\right)$ values $\delta^{I I c}{ }_{i}$ for pentylbutyrate (IIc) are calculated by formula (1) and represented in Table 2.

Calculated parameters $\delta_{2}^{I I c}=28.40 \mathrm{ppm}$ and $\delta^{I I c}=28.20 \mathrm{ppm}$ are close to experimental values from $[2]^{3}\left(\delta_{2}^{I I c}=28.51 \mathrm{ppm}\right.$ and $\left.\delta_{3}^{I I c}=28.23 \mathrm{ppm}\right)$. In the spectrum of IIc [3] there is a signal at $28.13 \mathrm{ppm}$ close to calculated parameter. We attribute it to $\mathrm{C}^{3}$ atom absorption. The other signal of IIc spectrum [3] exactly coincides with calculated value of parameter $\delta^{I I c}=28.40 \mathrm{ppm}$. The same as in case with acetate IIb, differential parameter $\Delta \delta^{I I c}$ obtained from calculated values $(28.40-28.20=$ $=+0.20 \mathrm{ppm})$ coincides with both values $\Delta \delta^{I I c}{ }_{2-3}$ calculated from experimental data: $(28.51-28.23=+0.28 \mathrm{ppm})$ [2] and $(28.40-28.13=+0.26 \mathrm{ppm})$ [3]. It should be noted that this value is less than both analogous parameters $\Delta \delta^{I I c}{ }_{2-3}$ calculated from experimental values $\delta^{C}$, the same as in case with acetate IIb.

\subsubsection{Pentylformate (IIa)}

The set of increments $\Delta \delta^{C}$ necessary for the calculation of $\delta^{C}$ values in pentylformate (IIa) is absent in [4]. Therefore, by analogy with the above-mentioned calculation for butyrates, values of increments for formates are calculated by formula (2) and tabulated in Table 3. For this purpose octylformate spectrum has been used because this compound is a formate with the longest alkyl chain among all given in [3] (in [2] octylformate spectrum is absent). By analogy with attributions of spectral data $\delta^{C}{ }_{i}$ for octylbutyrate and octylbenzoate made by the authors in [2] we assumed the following signal attributions in octylformate spectrum in [3]: $C^{1}=64.10 ; C^{2}=28.61$, $\mathrm{C}^{3}=25.91, \mathrm{C}^{4}=29.23, \mathrm{C}^{5}=29.23, \mathrm{C}^{6}=31.85, \mathrm{C}^{7}=22.71$, $\mathrm{C}^{8}=14.10$.

Using the set of increments $\Delta \delta^{C}{ }_{s}$ calculated for formates (see Table 3 ) we calculated values of all five parameters $\delta^{I I a}$, by formula (1). One can see from Table 2 that calculated parameter $\delta^{I I a}{ }_{2}=28.35 \mathrm{ppm}$ for $\mathrm{C}^{2}$ atom considerably differs from value $\delta^{I I a}{ }_{2}=28.11 \mathrm{ppm}$ given in [2] but practically coincides with parameter $\delta^{I I a}{ }_{3}=28.36$ ppm also given in [2]. On the contrary, the calculated parameter $\delta^{I I a}{ }_{3}=28.15 \mathrm{ppm}$ is considerably close to parameter $\delta_{2}^{I I a}=28.11 \mathrm{ppm}$ given in [2] but differs considerably from the signal at $28.36 \mathrm{ppm}$ which was attributed by the authors [2] to $\mathrm{C}^{2}$ atom adsorption.

The difference between $\delta^{I I a}$ and $\delta^{I I a}{ }_{3}$ signals attributions (assigned in [2] to $\mathrm{C}^{2}$ and $\mathrm{C}^{3}$ atoms in pentylformate (IIa) spectrum) and analogous correlations in other esters of 1-pentanol is greater for differential parameter $\Delta \delta^{I I a}{ }_{2-3^{*}}$. If we calculate it using attributions of basic parameters $\delta^{I I a}{ }_{2}$ and $\delta^{I I a}{ }_{3}$ given in [2], we will receive the negative value: $28.11-28.36=-0.25 \mathrm{ppm}$. If we use calculated values of basic parameters $\delta^{I I a}{ }_{2}$ and $\delta^{I I a}{ }_{3}$ (see Table 2), we will obtain practically the same value but with the opposite sign: $28.35-28.15=+0.20 \mathrm{ppm}$. It should be noted that all $\Delta \delta^{I I}{ }_{2-3}$ parameters for other esters of 1-pentanol - IIb, IIc and IId (see below) have commensurable values (from +0.15 to $+0.20 \mathrm{ppm}$ ) with obligatory positive sign.

All the mentioned above facts allow to assume that authors in [2] incorrectly attributed signals $\delta^{I I a}{ }_{2}=28.11$ and $\delta^{I I a}{ }_{3}=28.36 \mathrm{ppm}$ (see Table 1). To our mind it is necessary to interchange the mentioned signals, as it has been done in Table 2.

\subsubsection{Pentylbenzoate (IId)}

The same as in case with pentylformate (IIa) we calculated $\Delta \delta^{C}$ increments first. Their values are presented in Table 3 and calculated from spectral data $\delta^{I I d}{ }_{i}$ of octylbenzoate given in [2]: $\mathrm{C}^{1}=65.11 ; \mathrm{C}^{2}=28.82, \mathrm{C}^{3}=$ $=26.11, C^{4}=29.32^{*}, C^{5}=29.26^{*}, C^{6}=31.86, C^{7}=22.70$, $\mathrm{C}^{8}=14.10 \mathrm{ppm}^{4}$. Values of all five parameters $\delta^{I I d}{ }_{i}$ of

${ }^{3}$ In order to calculate basic spectral parameters $\delta^{C}$, of pentoxyl fragment it is enough to know increments for the first five carbon atoms in every set $\Delta \delta^{C}{ }_{r}$ or $\Delta \delta^{C}$. By the mentioned below reasons values of $\Delta \delta^{C}$ for eight carbon atoms in alkyl chain and for 10 and even 11 carbon atoms for butyrates are presented in Table 3. One can see from Table 3 that as far as we move to the middle of the chain an increment absolute value decreases and starting from $\mathrm{C}^{6}$ (in some cases from $\mathrm{C}^{7}$ or $\mathrm{C}^{8}$ ) tends to zero. Taking into account the approximate character of the whole conception about increment additivity, as well as stipulated accuracy of measurements, all increment values close to zero (till $\pm 0.10 \mathrm{ppm}$ ) should be considered as insufficiently reliable, especially if they are calculated from the spectrum of only one instance. By analogy with corresponding increments of alcohols and acetates it is possible that increment values for $\mathrm{C}^{6}-\mathrm{C}^{8}$ atoms are also insufficiently reliable. For $\mathrm{C}^{9}$ and higher atoms increments $\Delta \delta^{C}{ }_{s}$ are probably equal to zero.

${ }^{4}$ At calculation of $\Delta \delta^{C}$ increments for benzoates using the data for octylbenzoate [2] parameters marked with $*$ were exchanged. If they were not exchanged, neither the increment values $\Delta \delta_{4}(-0.45 \mathrm{ppm}$ instead of $-0.40 \mathrm{ppm})$ and $\Delta \delta_{5}(-0.15 \mathrm{ppm}$ instead of $-0.20 \mathrm{ppm})$ nor basic spectral parameters $\delta^{I l d}{ }_{4}(22.35 \mathrm{ppm}$ instead of $22.30 \mathrm{ppm})$ and $\delta^{I I d}{ }_{5}(13.90 \mathrm{ppm}$ instead of 13.95 ppm) would change. The mentioned exchange does not affect the basic spectral parameters $\delta_{2}^{I I d}$ and $\delta^{I I d}{ }_{3}{ }^{5}$ 
pentylbenzoate (IId) were calculated by formula (1) as in the previous cases. Calculated values $\delta^{I d}{ }_{2}=28.50 \mathrm{ppm}$ and $\delta^{I l b}{ }_{3}=28.35 \mathrm{ppm}$ are close to experimental values given in [2] $\left(\delta^{I I b}=28.58 \mathrm{ppm}\right.$ and $\left.\delta^{I I b}=28.32 \mathrm{ppm}\right)$; in [3] pentylbenzoate (IId) spectra are absent. Differential parameter $\Delta \delta^{I I d}{ }_{2-3}$ obtained from calculated parameters $\delta^{I I d}{ }_{2}$ and $\delta_{3}^{I I d}(28.50-28.15=+0.15 \mathrm{ppm})$ well coincides with $\Delta \delta^{I I d}{ }_{2-3}$ value calculated from [2] $(28.58-28.32=$ $=+0.26 \mathrm{ppm}$ ), the same as for aliphatic esters (IIa-IIc) of 1-pentanol. It should be noted that in case of pentylbenzoate (IId), calculated parameter is less than that obtained from experimental data [2]. The same regularity exists for all esters of aliphatic acids but not for 1-pentanol.

Spectral parameters $\delta^{I I e}{ }_{2}, \delta^{I I e}{ }_{3}$ and $\Delta \delta^{I I e}{ }_{2-3}$ for pentylbenzoylformate (IIe) will be discussed elsewhere.

\subsection{Pentyltosylate (III)}

Pentyltosylate (III) may be examined as ester of 1-pentanol (I) and para-toluene sulfonic acid. For tosylates there is a great amount of spectral data in [2] but they are absent in [3]. Using the above-mentioned procedures we calculated increments for tosylates based on the spectrum of octyltosylate - ester with the longest alkyl chain. The following $\delta^{I I I}{ }_{i}$ values were used [2]: $\mathrm{C}^{1}=70.72 ; \mathrm{C}^{2}=28.86$, $\mathrm{C}^{3}=25.36, \mathrm{C}^{4}=28.86^{*}, \mathrm{C}^{5}=29.06^{*}, \mathrm{C}^{6}=31.72, \mathrm{C}^{7}=$ $=22.61, \mathrm{C}^{8}=14.06 \mathrm{ppm}$. Parameters marked with $*$ were not exchanged, the results of calculations are represented in Table 3. In Table 2 there are values of all five parameters $\delta^{I I I}{ }_{i}$ for pentyltosylate (III) calculated by formula (1).

Calculated parameters of pentyltosylate (III) $\delta^{I I I}{ }_{2}=$ $=28.55 \mathrm{ppm}$ and $\delta^{I I}{ }_{3}=27.60 \mathrm{ppm}$ are close to experimental values given in [2]: $\delta^{I I}{ }_{2}=28.61 \mathrm{ppm}$ and $\delta^{I I I}{ }_{3}=27.53 \mathrm{ppm}$. The value of differential parameter $\Delta \delta^{I I I}{ }_{2-3}(28.55-27.60=$ $=+0.95 \mathrm{ppm}$ ) satisfactory coincides with the value $\Delta \delta^{I I I}{ }_{2-3}$, calculated using data from [2] $(28.61-27.53=+1.08 \mathrm{ppm})$. The same as for all esters (IIa-IId) but on the contrary to alcohol 1-pentanol (I), calculated parameter $\Delta \delta^{I I I}{ }_{2-3}$ is less than the experimental one $(0.95<1.08 \mathrm{ppm})$.

\subsection{Factors Affecting $\delta^{\tilde{N}}{ }_{2}$ and $\delta^{\tilde{N}}{ }_{3}$ Parameters in Compounds (I)- (III)}

It is known from [4] that the main factor affecting $\delta^{C}{ }_{i}$ value for every carbon atom in the linear chain of $\mathrm{CH}_{3}\left(\mathrm{CH}_{2}\right)_{\mathrm{n}} \mathrm{X}$ molecules is the sum of increments $r+s$ of the atom because the third summand in the formula (1) parameter $\delta^{c}{ }_{\text {mid. }}$ - is constant (29.75 ppm). Just the ratio between $\Delta \delta^{c}{ }_{r}$ and $\Delta \delta^{C}$ increments for every $\mathrm{C}^{2}$ and $\mathrm{C}^{3}$ atoms in compounds (I)-(III) determines the value of calculated basic spectral parameters $\delta^{C}{ }_{2}$ and $\delta^{C}{ }_{3}$.

For $\mathrm{C}^{2}$ atom increment $\Delta \delta^{C}{ }_{r}=\Delta \delta^{C}{ }_{\omega-2}=-0.30 \mathrm{ppm}$ in all compounds (I)-(III) is the same. Increments $\Delta \delta^{C}{ }_{s}$ for $\mathrm{C}^{2}$ atom considerably depend upon the structure of substituent $X$ (see Table 3). Increment $\Delta \delta^{I}$, for alcohols $(\mathrm{X}=\mathrm{OH})$ has a positive value $(+3.10 \mathrm{ppm})$, whereas it is negative for all examined esters including tosylates. Its value changes from $-0.90 \mathrm{ppm}$ for tosylates $\left(\Delta \delta^{I I I}{ }_{2}\right)$ to $1.15 \mathrm{ppm}$ for formates $\left(\Delta \delta^{I I a}{ }_{2}\right)$.

Calculated sum of $\Delta \delta^{C}{ }_{r}$ and $\Delta \delta^{C}{ }_{s}$ increments for $\mathrm{C}^{2}$ atom in all alcohols including 1-pentanol is positive and equal to: $+3.10-0.30=+2.80 \mathrm{ppm}$. Therefore, calculated values of parameters $\delta^{C}{ }_{2}=29.75+2.80=32.55 \mathrm{ppm}$ are the same for all alcohols. For esters this sum is negative and ranged from $-1.20 \mathrm{ppm}$ for tosylates to $-1.40 \mathrm{ppm}$ for formates and acetates. Hence calculated parameters $\delta^{C}$ for esters is less than $\delta^{C}{ }_{\text {mid. }}(29.75 \mathrm{ppm})$ by $1.2-1.4 \mathrm{ppm}$, i.e. their values are within an approximate interval of $28.35-28.55 \mathrm{ppm}$.

Similarly, for $\mathrm{C}^{3}$ carbon atoms in alkyl chains of compounds $\mathrm{CH}_{3}\left(\mathrm{CH}_{2}\right)_{\mathrm{n}} \mathrm{X}$ constant increment $\Delta \delta^{C}{ }_{r}=$ $=\Delta \delta^{C}{ }_{\omega-3}=+2.25 \mathrm{ppm}$ is a positive value. For alcohols and esters changeable increment $\Delta \delta^{c}{ }_{s}$ is a negative value (approximately $-4 \mathrm{ppm}$ ). It should be noted that absolute value of $\Delta \delta^{C}$ increment is greater than $\Delta \delta^{C}{ }_{r}$ increment, therefore their summary value is negative (approximately $-1.75 \mathrm{ppm})$. And since the interval where $\Delta \delta^{C}{ }_{s}$ increments can vary is relatively narrow (from $-3.65 \mathrm{ppm}$ for benzoates to -4.40 for tosylates), the sum of both increments $\Delta \delta^{C}{ }_{r}$ and $\Delta \delta^{c}{ }_{s}$ also varies in relatively narrow interval (from $-1.40 \mathrm{ppm}$ for benzoates to $-2.15 \mathrm{ppm}$ for tosylates). Calculated basic spectral parameters $\delta_{3}^{C}$ have approximate values of $28 \mathrm{ppm}$ (from $27.60 \mathrm{ppm}$ for tosylates to $28.35 \mathrm{ppm}$ for benzoates).

It should be noted also that both calculated parameters $\delta_{2}^{C}$ and $\delta_{3}^{C}$ are almost the same for esters (II) though $\delta_{3}^{C}$ is less than $\delta^{C}{ }_{2}$ by $0.2 \mathrm{ppm}$ on average. For tosylates the difference between calculated parameters $\delta^{C}{ }_{2}$ and $\delta_{3}^{C}$ is greater and equal to $0.95 \mathrm{ppm}$. We can explain this fact in the following way. As it was mentioned above, $\Delta \delta^{I I I}{ }_{s}$ increments forming this difference are boundary values in both intervals: absolute value of $\Delta \delta^{I I}{ }_{2}$ increment is a minimum and that of $\Delta \delta^{I I I}{ }_{3}$ increment is a maximum. Therefore their difference has the greatest value.

Thus, due to the random coincidence of the increments sum for $\mathrm{C}^{2}$ atom (from -1.2 to $-1.4 \mathrm{ppm}$ ) in pentoxyl derivatives (I)-(III) and for $\mathrm{C}^{3}$ atoms (from -1.4 to $-2.15 \mathrm{ppm}$ ) in esters (II)-(III), values of their calculated basic spectral parameters $\delta^{C}{ }_{2}$ and $\delta^{C}{ }_{3}$ are very close and equal to approximately $28 \mathrm{ppm}$. But in all cases the calculated adsorption of $\mathrm{C}^{2}$ atoms takes place in lower field than for $\mathrm{C}^{3}$ atoms.

Deviation of the calculated data $\delta^{C}{ }_{2}$ and $\delta^{C}{ }_{3}$ from the experimental ones [2, 3] for all examined compounds (excluding pentylformate IIa) does not exceed $0.1 \mathrm{ppm}$. 


\section{Conclusions}

The application of concept of increments additivity at calculation of $\delta^{C}$, signal chemical shifts in NMR ${ }^{13} \mathrm{C}$ spectra of compounds (I)-(III) allows to attribute every signal even in those cases when they differ by value more than $0.05 \mathrm{ppm}$. Using calculated parameters $\delta^{C}{ }_{2}$ and $\delta^{C}{ }_{3}$ for $\mathrm{C}^{2}$ and $\mathrm{C}^{3}$ atoms of 1-pentanol (I) and its esters (II)(III) it is possible to attribute signals close by their values in the area of $28 \mathrm{ppm}$ in $\mathrm{NMR}{ }^{13} \mathrm{C}$ spectra of such compounds. In case of pentylformate (IIa) on the basis of the calculated data it is suggested to interchange attributions made by authors [2].

The good accordance between given in "Appendix" calculated basic spectral parameters $\delta^{C}{ }_{i}$ for butanol, hexanol and heptanol as well as for their esters (formates, acetates, butyrates, benzoates and tosylates)

\section{Appendix}

Table 1

Attributions of experimental [2, 3] and calculated signals in NMR ${ }^{13} \mathrm{C}$ spectra of butanol and butyl esters to $\mathrm{C}^{1}-\mathrm{C}^{4}$ atoms

\begin{tabular}{|c|c|c|c|c|c|c|c|c|}
\hline \multirow{2}{*}{$\begin{array}{c}\delta_{i}^{C} \text { values }(\mathrm{ppm}) \text { in } \\
\text { compounds }\end{array}$} & \multicolumn{2}{|c|}{$\delta_{1}^{C}{ }_{1}$} & \multicolumn{2}{|c|}{$\delta_{2} C_{2}$} & \multicolumn{2}{|c|}{$\delta_{3}^{C}$} & \multicolumn{2}{|c|}{$\delta_{4}^{C}$} \\
\hline & Calc. & Exp. & Calc. & Exp. & Calc. & Exp. & Calc. & Exp. \\
\hline \multirow{2}{*}{ Butanol } & \multirow{2}{*}{62.70} & 62.30 & \multirow{2}{*}{35.10} & 34.85 & \multirow{2}{*}{18.75} & 19.09 & \multirow{2}{*}{13.85} & 13.92 \\
\hline & & 62.45 & & 34.87 & & 18.99 & & 13.89 \\
\hline \multirow{2}{*}{ Butylformate } & \multirow{2}{*}{63.80} & 63.94 & \multirow{2}{*}{30.85} & 30.72 & \multirow{2}{*}{18.85} & 19.18 & \multirow{2}{*}{13.65} & 13.66 \\
\hline & & 63.83 & & 30.64 & & 19.10 & & 13.62 \\
\hline \multirow{2}{*}{ Butylacetate } & \multirow{2}{*}{64.35} & 64.38 & \multirow{2}{*}{30.95} & 30.85 & \multirow{2}{*}{18.90} & 19.26 & \multirow{2}{*}{13.65} & 13.75 \\
\hline & & 64.34 & & 30.76 & & 19.20 & & 13.70 \\
\hline \multirow{2}{*}{ Butylbutyrate } & \multirow{2}{*}{64.10} & 64.11 & \multirow{2}{*}{30.95} & 30.90 & \multirow{2}{*}{18.90} & 19.29 & \multirow{2}{*}{13.65} & 13.73 \\
\hline & & 64.11 & & 30.81 & & 19.22 & & 13.71 \\
\hline \multirow{2}{*}{ Butylbenzoate } & \multirow{2}{*}{64.80} & 64.80 & \multirow{2}{*}{31.05} & 30.88 & \multirow{2}{*}{19.05} & 19.34 & \multirow{2}{*}{13.70} & 13.78 \\
\hline & & 64.80 & & 30.83 & & 19.31 & & 13.75 \\
\hline \multirow{2}{*}{ Butyltosylate } & \multirow{2}{*}{70.40} & 70.46 & \multirow{2}{*}{31.10} & 30.84 & \multirow{2}{*}{18.30} & 18.63 & \multirow{2}{*}{13.20} & 13.38 \\
\hline & & - & & - & & - & & - \\
\hline
\end{tabular}

Attributions of experimental [2, 3] and calculated signals in NMR ${ }^{13} \mathrm{C}$ spectra of hexanol and hexyl esters to $\mathrm{C}^{1}-\mathrm{C}^{6}$ atoms

\begin{tabular}{|c|c|c|c|c|c|c|c|c|c|c|c|c|}
\hline \multirow{2}{*}{$\begin{array}{c}\delta_{i}^{C} \text { values } \\
(\mathrm{ppm}) \text { in } \\
\text { compounds }\end{array}$} & \multicolumn{2}{|c|}{$\delta_{1}^{C}$} & \multicolumn{2}{|c|}{$\delta_{2}^{C}$} & \multicolumn{2}{|c|}{$\delta_{3}^{C}$} & \multicolumn{2}{|c|}{$\delta_{4}^{C}$} & \multicolumn{2}{|c|}{$\delta^{C}{ }_{5}$} & \multicolumn{2}{|c|}{$\delta_{6}^{C}$} \\
\hline & Calc. & Exp. & Calc. & Exp. & Calc. & Exp. & Calc. & Exp. & Calc. & Exp. & Calc. & Exp. \\
\hline \multirow{2}{*}{ Hexanol } & \multirow{2}{*}{63.00} & 62.80 & \multirow{2}{*}{32.80} & 32.79 & \multirow{2}{*}{25.50} & 25.59 & \multirow{2}{*}{31.75} & 31.80 & \multirow{2}{*}{22.65} & 22.75 & \multirow[t]{2}{*}{14.10} & 14.07 \\
\hline & & 62.86 & & 32.77 & & 25.52 & & 31.74 & & 22.69 & & 14.04 \\
\hline \multirow{2}{*}{ Hexylformate } & \multirow{2}{*}{64.10} & 64.13 & \multirow{2}{*}{28.55} & 28.61 & \multirow{2}{*}{25.60} & 25.59 & \multirow{2}{*}{31.35} & 31.49 & \multirow{2}{*}{22.50} & 22.61 & \multirow[t]{2}{*}{13.95} & 14.01 \\
\hline & & 64.10 & & 28.60 & & 25.57 & & 31.44 & & 22.56 & & 13.94 \\
\hline \multirow{2}{*}{ Hexylacetate } & \multirow{2}{*}{64.65} & 64.67 & \multirow{2}{*}{28.65} & 28.76 & \multirow{2}{*}{25.65} & 25.75 & \multirow{2}{*}{31.55} & 31.60 & \multirow{2}{*}{22.50} & 22.65 & \multirow[t]{2}{*}{14.10} & 14.03 \\
\hline & & 64.64 & & 28.66 & & 25.64 & & 31.49 & & 22.58 & & 13.98 \\
\hline \multirow{2}{*}{ Hexylbutyrate } & \multirow{2}{*}{64.40} & 64.39 & \multirow{2}{*}{28.65} & 28.79 & \multirow{2}{*}{25.65} & 25.73 & \multirow{2}{*}{31.55} & 31.57 & \multirow{2}{*}{22.50} & 22.64 & \multirow[t]{2}{*}{13.95} & 14.00 \\
\hline & & 64.38 & & 28.66 & & 25.64 & & 31.48 & & 22.58 & & 14.01 \\
\hline \multirow{2}{*}{ Hexylbenzoate } & 6510 & 65.04 & 2875 & 28.75 & 2580 & 25.74 & 3160 & 31.50 & 5250 & 22.58 & 13.95 & 13.98 \\
\hline & 05.10 & - & 28.15 & - & 25.80 & - & 31.00 & - & 22.50 & - & & - \\
\hline Hexyltosylate & 7070 & 70.74 & 2880 & 28.82 & 2505 & 25.03 & 3110 & 31.11 & 2230 & 22.43 & 13.80 & 13.91 \\
\hline & & - & & - & & - & & - & & - & & \\
\hline
\end{tabular}


Attributions of experimental $[2,3]$ and calculated signals in NMR ${ }^{13} \mathrm{C}$ spectra of heptanol and heptyl esters to $\mathrm{C}^{1}-\mathrm{C}^{7}$ atoms

\begin{tabular}{|c|c|c|c|c|c|c|c|c|c|c|c|c|c|c|}
\hline \multirow{2}{*}{$\begin{array}{c}\delta^{C}{ }_{i} \text { values } \\
\text { (ppm) in } \\
\text { compounds }\end{array}$} & \multicolumn{2}{|c|}{$\delta^{C}{ }_{1}$} & \multicolumn{2}{|c|}{$\delta_{2}^{C}$} & \multicolumn{2}{|c|}{$\delta_{3}^{C}$} & \multicolumn{2}{|c|}{$\delta_{4}^{C}$} & \multicolumn{2}{|c|}{$\delta^{C}{ }_{5}$} & \multicolumn{2}{|c|}{$\delta_{6}^{C}$} & \multicolumn{2}{|c|}{$\delta_{7}^{C_{7}}$} \\
\hline & Calc. & Exp. & Calc. & Exp. & Calc. & Exp. & Calc. & Exp. & Calc. & Exp. & Calc. & Exp. & Calc. & Exp. \\
\hline \multirow{2}{*}{ Heptanol } & \multirow{2}{*}{63.00} & 62.67 & \multirow{2}{*}{32.85} & 32.84 & \multirow{2}{*}{25.75} & 25.93 & \multirow{2}{*}{29.20} & 29.31 & \multirow{2}{*}{31.95} & 32.01 & \multirow[t]{2}{*}{22.70} & 22.75 & \multirow[t]{2}{*}{14.10} & 14.11 \\
\hline & & 62.94 & & 32.80 & & 25.77 & & 29.15 & & 31.86 & & 22.65 & & 14.09 \\
\hline \multirow{2}{*}{ Heptylformate } & \multirow{2}{*}{64.10} & - & \multirow{2}{*}{28.60} & - & \multirow{2}{*}{25.85} & & \multirow{2}{*}{29.00} & & \multirow{2}{*}{31.80} & - & \multirow[t]{2}{*}{22.55} & - & \multirow[t]{2}{*}{14.05} & - \\
\hline & & 64.12 & & 28.57 & & 25.82 & & 28.89 & & 31.74 & & 22.60 & & 14.06 \\
\hline \multirow{2}{*}{ Heptylacetate } & \multirow{2}{*}{64.65} & 64.64 & \multirow{2}{*}{28.70} & 28.81 & \multirow{2}{*}{25.95} & 26.04 & \multirow{2}{*}{29.00} & 29.06 & \multirow{2}{*}{31.80} & 31.89 & \multirow[t]{2}{*}{22.70} & 22.69 & \multirow[t]{2}{*}{14.10} & 14.07 \\
\hline & & - & & - & & - & & - & & - & & - & & - \\
\hline \multirow{2}{*}{ Heptylbutyrate } & \multirow{2}{*}{64.40} & - & \multirow{2}{*}{28.70} & - & & - & & . & & - & 22.55 & - & 14.00 & - \\
\hline & & 64.38 & & 28.71 & 25.90 & 25.98 & 29.00 & 28.95 & 31.00 & 31.77 & & 22.61 & & 14.07 \\
\hline Hentylhenzoate & 6510 & 65.13 & 2880 & 25.82 & 2605 & 26.09 & 2005 & 29.02 & 3180 & 31.81 & 22.55 & 22.66 & 14.05 & 14.07 \\
\hline & & - & & - & & - & & - & & - & & & & \\
\hline Heptyltosylate & 70.70 & 70.72 & 28.85 & $28.87^{*}$ & 25.30 & 25.31 & 28.55 & $28.58^{*}$ & 31.60 & 31.58 & 22.40 & 22.49 & 13.95 & 14.00 \\
\hline & & - & & - & & - & & - & & - & & & & \\
\hline
\end{tabular}

and experimental data $[2,3]$ is an indirect evidence of the true attributions of $\delta^{C}$ signals in NMR ${ }^{13} \mathrm{C}$ spectra of compounds (I)-(III).

\section{References}

[1] Shybanov V., Mizyuk V. and Kobryn L.: Voprosy Khim. i Khim. Techn., 2005, 5, 51.

[2] http://www.aist.go.jp.

[3] Aldrich/ACD Library of FT NMR Spectra (Pro) Data Base Window.

[4] Mizyuk V., Marshalok I. and Shybanov V.: XI conference "Lviv Chemistry readings", Lviv 2009, O24.
РОЗРАХУНОК СПЕКТРІВ ЯМР ${ }^{13}$ С 1-ПЕНТАНОЛА ТАЙОГО ЕСТЕРІВ - ПРИКЛАД ЕФЕКТИВНОГО ВИКОРИСТАННЯ ПРИНЦИПУ АДИТИВНОСТІ

ІНКРЕМЕНТІВ ХІМІЧНИХ ЗСУВІВ ДЛЯ ВІДНОШЕННЯ СИГНАЛІВ В СПЕКТРАХ

\section{АЛФАТИЧНИХ СПОЛУК}

Анотація. Застосування принципу адитивності інкрементів при розрахунках хімічних зсувів $\delta^{C}{ }_{2}$ ma $\delta^{C}{ }_{3}$ для атомів $C^{2}$ i $C^{3}$ 1-пентанолу (I) та його естерів (II, III) дало можливість обтрунтовано віднести близькі за величиною сигнали в області 28 м.ч. в спектрах ЯМР ${ }^{13}$ С цих сполук. У випадку пентилформіату (IIа) на основі розрахункових даних запропоновано поміняти місиями віднесення, зроблені авторами [2].

Ключові слова: спектри ЯМР ${ }^{13} \mathrm{C}$, базові та диференційні параметри, 1-пентанол та його естери, хімічні зсуви. 